\title{
Editorials
}

\section{Mental health system financing in developing countries: Policy questions and research responses*}

\author{
DAN CHISHOLM
}

\begin{abstract}
To what extent does previous and existing health economics research directly address key health system financing issues facing mental health services in developing countries? By mapping WHO's health systems framework onto mental health, three key financing questions for mental health are identified: the sufficiency of resources for mental health; the protection of individuals or households against the economic consequences of mental ill-health; and the efficient use of available resources for mental health. Research efforts to date have mainly focused on the evaluation of intervention costs in relation to mental health outcomes (the efficiency question). There is a need to achieve a greater balance between economic analysis (aimed at identifying best buys) versus financial planning (scaling up the delivery or implementation of interventions shown to be cost-effective). In addition, a better understanding and clearer articulation of the negative impact of mental disorders at the household level is needed, together with ways of alleviating financial burden via appropriate and affordable pre-payment financing mechanisms.
\end{abstract}

\section{INTRODUCTION}

The last two decades have seen an ever-increasing interest in, and demand for, economic or financial analysis of mental health care and policy, fuelled by government concerns about rises in health care expenditures (Dixon et al., 2006; Singh et al., 2001; World Health Organization, 2006). Prompted by the pervasive scarcity of resources relative to health needs and demands, economic and financial considerations can and do enter into health care reform processes, priority-setting exercises within and across health programmes, and regulatory decisions concerning drug approval or pricing (Araya $e t$ al., 2006; Drummond et al., 1997; Hutubessy et al., 2003).

In this policy review, a discrete number of key health system financing challenges facing mental health services in developing countries are identified, with a view to assessing the extent to which previous and existing health economics research directly addresses these issues. By so doing, a better appreciation of knowledge gaps or future research directions can be elicited.

Address for correspondence: Dr. D. Chisholm, Department of Health Systems Financing, World Health Organization, Geneva (Switzerland).

E-mail: ChisholmD@WHO.int

Declaration of Interest: None

*The views expressed in this editorial are those of the author and are not necessarily those of the World Health Organization.

\section{OBJECTIVES AND FUNCTIONS OF A MENTAL HEALTH SYSTEM}

In order to introduce some structure and objectivity around the question of what mental health policy issues should be addressed by economics research, a conceptual framework is needed. The health system framework used here is that of the World Health Organization (WHO), which was first set out in the World Health Report 2000 (World Health Organization, 2000) and continues to be used by WHO with only minor modification (World Health Organization, 2007). Essentially, it proposes that while health improvement is unquestionably the primary goal of a health system, two other (social) goals are also important: the first is fair financing in health, which seeks to ensure that the financial risks each household faces with respect to health are distributed fairly, that is, according to their ability to pay; and the second has to do with how well the health system responds to the reasonable expectations of the people it seeks to serve, such as ensuring the quality of health facilities and preserving respect for the dignity of the system user. Similar goals have been applied within the context of mental health policy and planning in a number of developed and developing countries, including the pursuit of improved psychological well-being in the population, quality improvements in mental health service provision, and financial (as well as human rights) protection for the mentally ill (World Health Organization, 2004; p. 28-29). 
Concerning the health financing functions and objectives, all health financing systems, however organized, share three key functions: revenue collection (i.e. how financial contributions are collected from different sources, and via what mechanism (tax, insurance etc.); pooling (i.e. how financial contributions are pooled together so that the risk of having to pay for health care is not borne by each contributor individually); and purchasing/provision (i.e. how contributions are used to purchase or provide health services). By rephrasing these financing functions into questions, the following key challenges emerge:

1. Revenue collection: Are there sufficient funds available for (mental) health?

2. Pooling: Are vulnerable individuals or households adequately protected from the financial consequences of their (mental) ill-health?

3. Purchasing: Are available resources for (mental) health service provision being used to best effect?

The question of interest here is whether mental health economics research in developing countries is well targeted on these key health system financing challenges.

\section{ARE THERE SUFFICIENT FUNDS AVAILABLE FOR (MENTAL) HEALTH?}

From an economic perspective, it is always tempting to point out that if only resources were more carefully targeted towards the priority health needs of the population, more benefit could be obtained from existing levels of expenditure. While the search for such improvements is certainly needed (see below), it is important to distinguish between the relative efficiency with which resources are allocated versus the absolute quantity of resources available in the first place. Thirty nine of the 192 countries that are members of the World Health Organization (WHO), and for which data are available, spent less than US\$25 per capita on health in 2004, and 60 spent less than US $\$ 50$ (www.who.int/nha). This includes funding from all sources - external and national donors, governments, firms and household out-of-pocket contributions. This level of funding is just not sufficient to ensure universal access to even a minimum level of basic health services, estimated to cost somewhere between US\$35 and $\$ 50$ per capita depending on the country (World Health Organization, 2000; 2001). These estimates exclude mental health care and support.
Funding for mental health services is low relative to identified needs for services at the population level (Saxena et al., 2003; 2007). 30\% of 184 countries recently surveyed as part of the ATLAS project did not have a specified mental health budget (World Health Organization, 2005). Of those that do, $20 \%$ spend less than $1 \%$ of the total health budget on mental health (mostly in Africa and South-East Asia). By simply multiplying total health spending (as a \% of GDP, for example) by mental health spending (as a \% of total health spending), it quickly becomes apparent that there is an order-of-magnitude difference between low-income versus high-income countries. To illustrate, many highincome countries spend in the order of $1 \%$ of their current wealth on mental health (e.g. 10\% of GDP on health, of which $10 \%$ is on mental health), whereas low-income countries spend a fraction of this amount (e.g. 3\% of GDP on health, of which $3 \%$ on mental health). So for a low-income country with a GDP per capita of only US\$ 3,000 , annual spending on mental health would be around $\$ 3$, compared to $\$ 300$ in a high-income country with a GDP of $\$ 30,000$ per capita.

This leads to a related question: if not enough now, how much is needed in the future? Given the very modest starting-point in most countries, the cost of dramatically increasing the mental health workforce and its capacity to provide appropriate care or prevention to identified populations in need could be considerable. A recent financial analysis estimated the expected costs of substantially scaling up the coverage or implementation of a defined package of treatment and care for schizophrenia, bipolar disorder, depression and hazardous alcohol use in 12 lowand middle-income countries (Chisholm et al., 2007). The authors found that in order to meet the specified target coverage levels - $80 \%$ of cases for schizophrenia and bipolar disorder, and $25-33 \%$ of cases with depression and risky drinking - spending for this package alone would need to be around $\$ 2$ per capita in low-income countries (compared to $\$ 0.10-0.20$ now), and $\$ 3-4$ in middle-income countries. So for a middle-income country of 50 million people, total annual expenditure for the package would amount to $\$ 150-200$ million.

At a condition-specific level, two separate studies undertaken in India estimated the cost of episodic treatment of depression with antidepressants in primary care to be $150-300$ rupees per month, equivalent to about US\$ 20-40 for a 6-month treatment episode (Chisholm et al., 2000; Patel et al., 2003). Using international drug prices and including costs of training and programme administration, an analysis for the South-East Asia region as a whole put the 6-month cost of treatment at US\$ $30-60$ for 
TCAs and US\$ 60-80 for SSRIs (Chisholm et al., 2004). The price of generic SSRIs has continued to fall, with latest available prices ( $\$ 2-3$ for 100 daily doses of $20 \mathrm{mg}$ fluoxetine) indicating that treatment costs using this category of drug are now equivalent to using older antidepressants. An investment of $\$ 5-10$ per month for someone with depression does not seem unduly costly, just so long as it is produces a reasonable return in terms of health and other gains.

Additional estimation exercises of this kind - for specific diseases as well as defined packages - are certainly required in order to inform efforts to inform planning and revitalize investment in mental health systems in different regions of the developing world.

\section{ARE VULNERABLE INDIVIDUALS OR HOUSEHOLDS ADEQUATELY PROTECTED FROM THE FINANCIAL CONSEQUENCES OF THEIR (MENTAL) ILL-HEALTH?}

Concerning pooling of funds, there are now good data on the relative contribution of different financing mechanisms towards the cost of mental health care provision, both at the country and regional level (World Health Organization, 2005). While tax-based financing is the most common mechanism, it is of particular note that outof-pocket expenditure by households is also a commonly used mechanism for purchasing mental health services in certain, mainly low-income, regions of the world. WHO's Mental Health Atlas (World Health Organization, 2005) figures demonstrate that $17.8 \%$ of 121 countries reporting on this aspect had out-of-pocket payment as the most common method of financing mental health care.

It is widely acknowledged that out-of-pocket payments are a regressive form of health financing (they penalise those least able to afford care) and represent an obvious channel through which impoverishment may occur. Specifically, they lead in many cases to health spending levels that have been labelled 'catastrophic' because they cause households to reallocate their budgets away from other essential needs such as education, food and housing. The potentially 'catastrophic' impact of private, out-of-pocket payments on the income and savings of households with a mentally ill member was assessed in a recent study in the state of Goa in India (Patel et al., 2007; see also Figure 2), which found that $15 \%$ of women with a common mental disorder spent more than $10 \%$ of

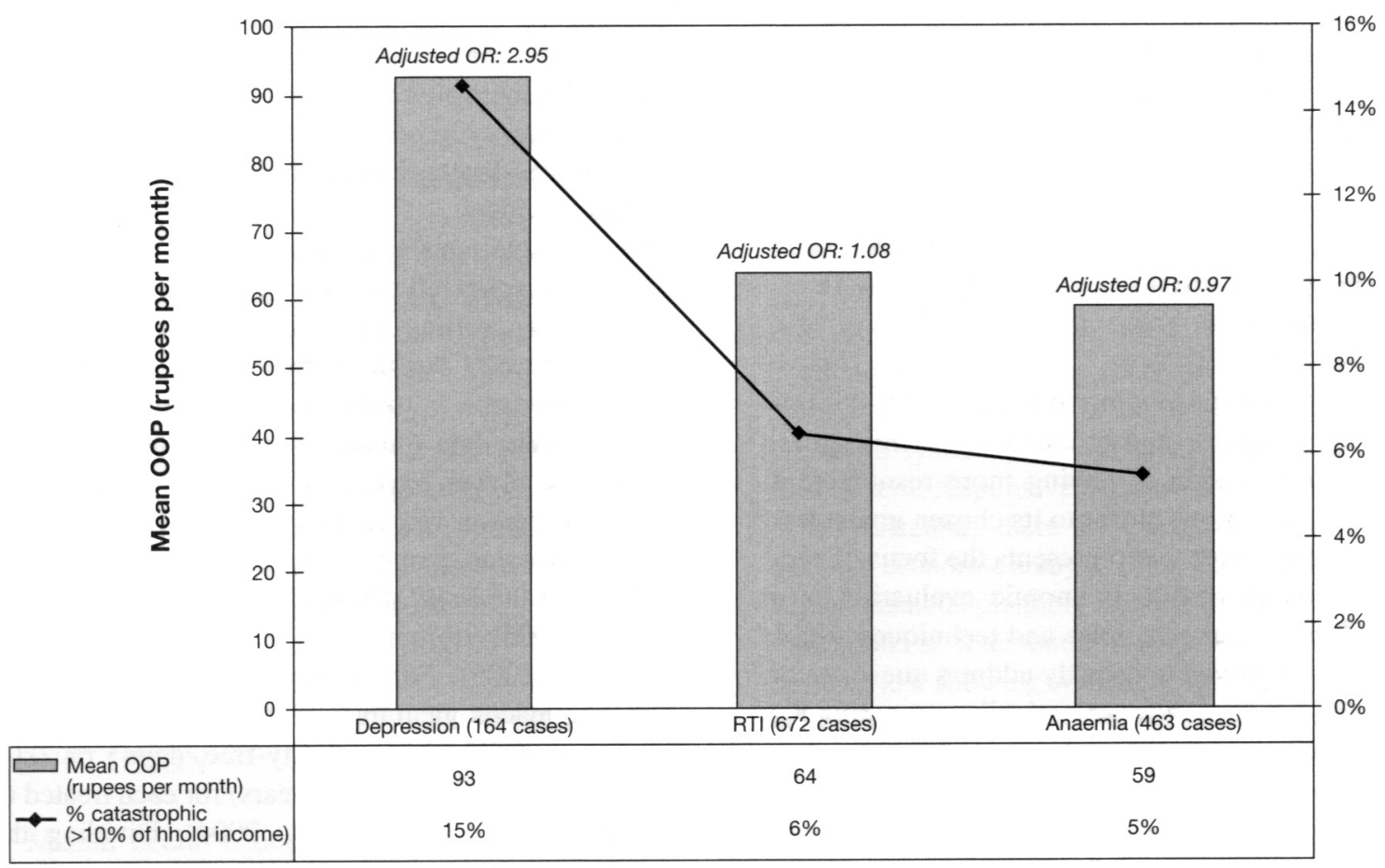

Figure 2. - Comparative financial impact of disease on households (Source: Patel et al., 2007) 
household income on health-related expenditures. By contrast, a study undertaken in the US concluded that outof-pocket spending did not represent a substantial source of financial burden for most service users (Ringel \& Sturm, 2001), since most expenditures are financed by insurers or managed care organisations.

Just because of the low rates of (national, social or private) insurance in developing countries and the consequently high level of dependence on 'paying as you go', assessment of the economic consequences of different financing mechanisms on mental health outcomes, equity and impoverishment would appear to be a highly relevant but vastly under-researched topic of research (see Dixon et al., 2006 for a review). At the household level, costs incurred in the acquisition of mental health or welfare services should represent the resources that could have been used for other types of consumption or investment had the disease or illness not occurred (McIntyre et al., 2006). However, very few studies have measured the consequences of mental illness on households, for example in terms of the impact of out-of-pocket expenditures and lost work days on future consumption opportunities (e.g. via depleted savings, assets or human capital formation / education). For example, existing 'cost-of-illness' studies of psychiatric disorders have little to say on the myriad impacts of mental ill-health on households (current and future consumption, paid and unpaid production), even though this would constitute the primary measurement level in countries with low rates of health care insurance and/or coverage.

\section{ARE AVAILABLE RESOURCES FOR (MENTAL) HEALTH SERVICE PROVISION BEING USED TO BEST EFFECT?}

The final key challenge facing (mental) health systems relates to the appropriate and efficient use of resources. Greater efficiency is akin to having more resources; it allows the system to move closer to its chosen goals. It is this efficiency objectives that represents the focus of economic evaluation in health. Economic evaluation provides a set of analytical principles and techniques which can be usefully employed to directly address questions of efficiency, which it does by systematically comparing the relative costs and consequences of different health intervention strategies.

Despite the need for cost-effectiveness evidence, there remains a relative paucity of completed mental health economic evaluations from developing countries (Shah \& Jenkins, 2000). A recent systematic review of the evalu- ative literature around community mental health over the last decade found that only four out of the 20 studies meeting inclusion criteria contained a cost or economic component (Wiley-Exley, 2006). This does not represent a sufficient basis for determining efficient ways of responding to the substantial and growing burden of mental disorders in developing countries. But even this slim body of evidence has been able to demonstrate the feasibility and relevance of including such considerations into the evaluative framework. For example, three separate mental health economic studies have been carried out in India: a prospective population-based study of the costs and effects of integrating mental health into primary care (Chisholm et al., 2000); a randomized cost-effectiveness trial of treatment of common mental disorders (Patel $e t$ al., 2003); and a prospective follow-up study of untreated schizophrenia patients (Srinivasa Murthy et al., 2005). While each of these studies address different questions, use different study designs and relate to different diagnostic categories, they have consistently shown positive effects of intervention on costs as well as outcomes (see, for example, Figure 3, which tracks changes in cost and disability level over an 18 month period for schizophrenia patients exposed to a community outreach programme). In addition, and this also relates to the financing and economic impact issue, these studies consistently show that out-of-pocket medical expenses (mostly for informal care sector visits), informal care-giving by household members plus other time and travel costs make up the vast majority of costs at baseline, and exceed subsequent costs of targeted clinical intervention by public heath care providers.

While multiple empirical studies at the national level offer the ideal approach to generating an economic evidence base for setting priorities for and allocating resources to mental health in developing countries, an alternative approach is to use modeling techniques and already available data (mostly from high-income countries). Such analyses have now been completed for a range of disorders or risk factors (schizophrenia, bipolar disorder, depression, panic disorder, epilepsy, hazardous alcohol use) at the level of World Bank or WHO regions (Chisholm, 2005; Hyman et al., 2006; World Health Organization, 2006). For example, compared to doing nothing, pharmacological treatment of depression is estimated to avert 20-22 'disability-free days' or 0.06 DALYs (disability-adjusted life-years) for each treated 6month episode (Chisholm et al., 2004). Dividing the treatment costs mentioned above $(\$ 30-60)$ by total effects (0.06 DALYs) produces cost-effectiveness ratios in the range US\$ 500-1,000 per DALY averted, which is in the 


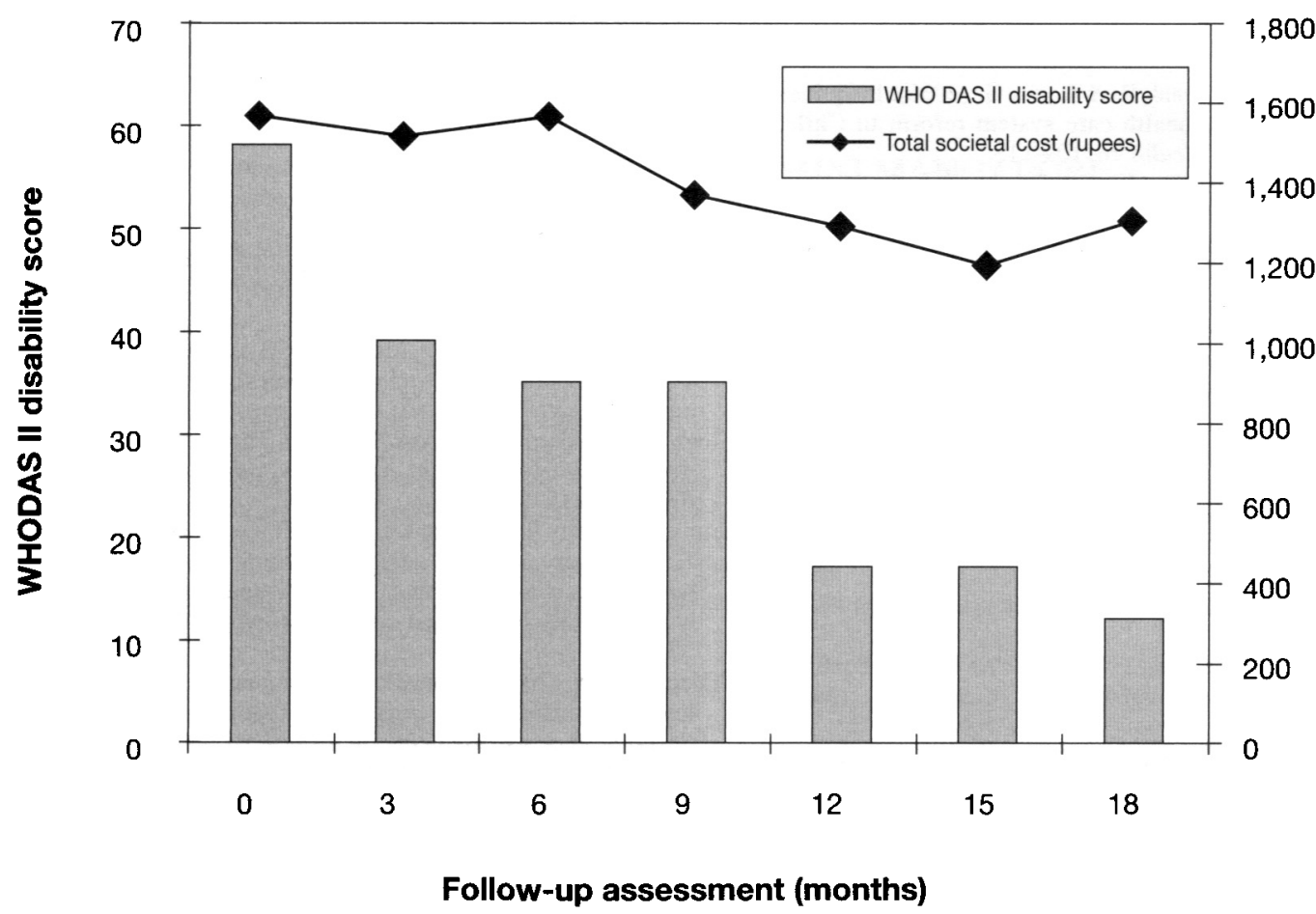

Figure 3. - Changes in disability and costs following community outreach treatment of untreated schizophrenia in rural India (Source: Srinivasa Murthy et al., 2005).

same range as interventions for other chronic non-communicable conditions, such as secondary prevention of hypertension or glycaemic control for diabetes. A further example relates to pharmacological treatment of schizophrenia in developing countries, with analysis indicating that on economic efficiency grounds the newer 'atypical' anti-psychotic drugs are not an affordable choice at current prices (older drugs have similar effectiveness and cost much less). Such regional-level analysis can and does act as a baseline from which to tailor results to the national level, a process that has now been undertaken in a number of countries worldwide (World Health Organization, 2006).

\section{CONCLUSION}

Mental health economics research in the context of developing countries is at an early stage of development, but as the momentum for increased action and investment in mental health system development builds, the need or demand for such research can only increase. Research efforts to date have mainly focused on the evaluation of intervention costs in relation to mental health outcomes, either at the national or the global level. But as shown in this review, an objective view of key health financing challenges suggests that there are other, equally important issues that need to be better addressed if other mental health system goals are to be achieved (fair financing plus decent, responsive services for the user).

In particular, there is a need to achieve a balance between economic analysis (aimed at identifying best buys) versus financial planning (scaling up the delivery or implementation of interventions shown to be cost-effective), because just showing something to be a wise use of available resources does not amount to very much if this does not translate into actual changes in the way services are financed and delivered. A further related area of great importance is to better understand the negative impact of mental disorders or addiction at the household level, together with ways of alleviating financial burden via appropriate and affordable pre-payment financing mechanisms. 


\section{Chisholm}

\section{REFERENCES}

Araya R., Rojas G., Fritsch R., Frank R. \& Lewis G. (2006). Inequities in mental health care after health care system reform in Chile. American Journal of Public Health 96, 109-113.

Chisholm D. (2005). Choosing cost-effective interventions in psychiatry. World Psychiatry 4, 37-44.

Chisholm D., Kumar K., Sekar K., Saeed K., James S., Mubbashar M. \& Srinivasa Murthy R. (2000). Integration of mental health care into primary care: a demonstration cost-outcome study in India and Pakistan. British Journal of Psychiatry 176, 581-588.

Chisholm D., Sanderson K., Ayuso-Mateos J.L. \& Saxena S. (2004) Reducing the burden of depression: a population-level analysis of intervention cost-effectiveness in 14 epidemiologically-defined sub-regions (WHO-CHOICE). British Journal of Psychiatry 184, 393-403.

Chisholm D., Lund C. \& Saxena S. (2007). Cost of scaling up mental healthcare in low - and middle-income countries. British Journal of Psychiatry 191, 528-535.

Dixon A., McDaid D., Knapp M. \& Curran C. (2006). Financing mental health services in low- and middle-income countries. Health Policy and Planning 21, 171-182.

Drummond M., Jonsson B. \& Rutten F. (1997). The role of economic evaluation in the pricing and reimbursement of medicines. Health Policy 40, 199-215.

Hutubessy R., Chisholm D. \& Edejer T.T. (2003). Generalized cost-effectiveness analysis for national-level priority-setting in the health sector. Cost Effectiveness and Resource Allocation 1, 8.

Hyman S., Chisholm D., Kessler R., Patel V. \& Whiteford H. (2006). Mental disorders. In Disease Control Priorities in Developing Countries (2nd Ed.)(ed. D. Jamison, J. Breman, A. Measham, G. Alleyne, D. Evans, P. Jha, A. Mills, P. Musgrove). Oxford University Press: New York.

McIntyre D., Thiede M., Dahlgren G. \& Whitehead M. (2006). What are the economic consequences for households of illness and of paying for health care in low- and middle-income country contexts? Social Science and Medicine 62, 858-865.

Patel V., Chisholm D., Rabe-Hesketh S., Dias-Saxena F., Andrews G. \& Mann A. (2003). Efficacy and cost-effectiveness of drug and psychological treatments for common mental disorders in general health care in Goa, India: a randomised, controlled trial. Lancet 361, 33-39.

Patel V., Chisholm D., Kirkwood B.R. \& Mabey D. (2007). Prioritizing health problems in women in developing countries: comparing the financial burden of reproductive tract infections, anaemia and depressive disorders in a community survey in India. Tropical Medicine and International Health 12, 130-139.
Ringel J.S. \& Sturm R. (2001). Financial burden and out-of-pocket expenditures for mental health across different socioeconomic groups: Results from healthcare for communities. Journal of Mental Health Policy and Economics 4, 141-150.

Saxena S., Sharan P. \& Saraceno B. (2003). Budget and financing of mental health services: baseline information on 89 countries from WHO's project atlas. Journal of Mental Health Policy and Economics 6, 135-143.

Saxena S., Thornicroft G., Knapp M. \& Whiteford H. (2007). Resources for mental health: scarcity, inequity and inefficiency. Lancet 370 , 878-889.

Shah A. \& Jenkins R. (2000). Mental health economic studies from developing countries reviewed in the context of those from developed countries. Acta Psychiatrica Scandinavica 100, 1-18.

Singh B., Hawthorne G. \& Vos T. (2001). The role of economic evaluation in mental health care. Australian and New Zealand Journal of Psychiatry 35, 104-117.

Srinivasa Murthy R., Kishore Kumar K., Chisholm D., Thomas T., Sekar K. \& Chandrashekar C. (2005). Community outreach for untreated schizophrenia in rural India : a follow-up study of symptoms, disability, family burden and costs. Psychological Medicine 35, 341351.

Wiley-Exley E. (2006). Evaluations of community mental health care in low- and middle-income countries: a 10-year review of the literature. Social Science and Medicine 64, 1231-1241.

World Health Organization (2000). World Health Report 2000; Health Systems: Improving Performance. WHO: Geneva.

World Health Organization (2001). Macroeconomics and Health: Investing in Health for Economic Development. Report of the Commission on Macroeconomics and Health. WHO: Geneva.

World Health Organization (2004). Mental Health Policy, Plans and Programmes. Mental health Policy and Service Guidance Package. WHO: Geneva.

World Health Organization (2005). Atlas: Mental Health Resources in the World 2005. WHO, Geneva. Retrieved September 26, 2007, from http://www.who.int/mental_health

World Health Organization (2006). Dollars, DALYs and Decisions: Economic Aspects of the Mental Health System. WHO: Geneva. Retrieved April 22, 2007 from http://www.who.int/mental_health/ evidence

World Health Organization (2007). Everybody's Business: Strengthening Health Systems to improve Health Outcomes. WHO Geneva. Retrieved November 8, 2007, from http://www.who.int/ healthsystems/strategy 